\title{
LEVOSEMINDAN VERSUS INTRA-AORTIC BALLOON PUMP IN LOW EJECTION FRACTION CABG PATIENTS
}

\author{
Shereif Elsayed Soliman Azzab*, Yasser Mahmoud Elnahas* Ibrahim Shawky \\ Elkelany*and Ahmed Mohamed Abd El-Salam Moharm**
}

\begin{abstract}
:
*Cardiothoracic Surgery, Faculty of Medicine Ain Shams University, ** Nasser Institute for research and treatment, Ministry of Health, Cairo, Egypt.

Corresponding author

Ahmed M. Abd Elsalam Moharm

Mobile: (+2) 01062443367;

Background: Preoperative left ventricular dysfunction is an independent risk factor for perioperative mortality and morbidity and is also associated with postoperative low cardiac output syndrome. IABP improved outcomes in high-risk cardiac patients. However, installation of the balloon has many disadvantages. Recently, a new drug named Levosimendan is commonly used as an inotropic support. it does not increase oxygen demand of myocardium.
\end{abstract}

E.mail:

ahmedmoharm255@gmail.com

Received: 30/12/2020

Accepted: 21/1/2021

Online ISSN: 2735-3540
Aim of the work: The purpose of our study was to compare the efficiency of levosimendan versus intra-aortic balloon pump in patients with poor left ventricular function undergoing coronary artery bypass grafting $(C A B G)$ with ejection fraction less than $35 \%$.

Patients and Methods: sixty patients were randomized into 2 groups, according to the treatment they received - either levosimendan (Group A) or intra-aortic balloon counter pulsation (Group B). and compared with respect to The use of inotropic drugs, weaning from $C P B$, Hemodynamics, transfusion requirements, ICU stay, hospital stay and in-hospital mortality.

Results: There were no differences in preoperative characteristics including patients' age, sex, BMI, and comorbidities. The Levosemindan group had reduced transfusion requirements and shorter ICU stay as compared to IABP group.

Conclusion: levosimendan infusion after induction of anesthesia is a good choice with an acceptable option in comparison to IABP. The use of levosimendan in high-risk cardiac patients is comparable to IABP in improving hemodynamics during and after conventional on-pump CABG and results in a shorter ICU stay.

Key words: CABG, Levosmindan, Intra aortic balloon pump, Left ventricular dusfunction .

\section{INTRODUCTION:}

Worldwide, the number of patients with congestive heart failure is constantly increasing and The most frequent cause of congestive heart failure is coronary artery disease $^{(1)}$. Medical treatment in patients with low myocardial contractility does not have a clear positive effect on the symptoms of heart failure or survival so patients, under gone of myocardial revascularization has many advantages over drug therapy ${ }^{(2)}$. Surgical revascularization was appeared to provide excellent decline of symptoms as well as improved survival among patients with the most severe forms of coronary heart disease involvement.

Post cardiotomy low cardiac output syndrome (LCOS) occurs in $20 \%$ of patients undergoing open-heart surgery, and is related to increased hospital mortality, morbidity 
and $\operatorname{costs}^{(3)}$.

Its occurrence is more frequent in patients with severe pre operative left ventricular dysfunction. Acute worsening of the left heart failure is commonly treated pharmacologically with intravenous positive inotropic agents, or mechanical support in severe cases such as an intra-aortic balloon pump (IABP) ${ }^{(4)}$. The choice of method for hemodynamic support is the crucial moment in the management of such patients

Intra-Aortic Balloon Pump (IABP) is now the most commonly used therapeutic option to support failing heart in cardiac surgery. The main effect of IABP is to increase the diastolic blood pressure ,therefore an improvement in coronary perfusion and a reduction of ventricular after load, thus increasing stroke volume and cardiac output, the device installed on cardiac revascularization preoperative in patients with severe cardiac dysfunction has been shown as an important impact strategy to decrease morbid-mortality ${ }^{(5,6)}$ however IABP related complications include limb ischemia .bleeding at the site of IABP insertion, infection and aortic dissecion ${ }^{(7)}$.

Levosimendan is a recently introduced calcium sensitizer. It enhances myocardial contractility by sensitization of troponin $\mathrm{c}$ to calcium, that enhances myofilament responseveness to calcium, thereby increasing myocardial contraction without a simultaneous increase in oxygen consumption and provides systemic ,pulmonary and coronary arterial and venous vasodilatation due to activation of the ATP- sensitive potassium channels in smooth muscle fibers. It has been reported that Levosimendan facilitated weaning from $\mathrm{CPB}$ in high risk patient groups by reducing pulmonary arterial pressure and increasing both right and left ventricular contractility ${ }^{(8)}$.

\section{AIM OF THE WORK:}

The aim and purpose of this study is to compare the use of levosimendan versus an IABP in patients with poor left ventricular function undergoing coronary artery bypass graft surgery(CABG) .

\section{PATIENTS AND METHODS:}

This retrospective non randomized study was performed at Department of cardiac surgery at Nasser institute for research and treatment Hospital, in Egypt in the period between July 2019 and February 2020. The study was previously approved by the Ethics Committee for Clinical Research of the institutions. The study that included 60 patients, women and men, All patients presented with coronary insufficiency confirmed by coronary angiographic studies and Pre-operative echocardiography revealed poor left ventricular function Ejection fraction less than $35 \%$. who underwent coronary artery bypass grafting, were included in this study. These patients were allocated and divided into two groups 30 in Group A patients will be submitted to levosimendan intra-aortic balloon and Group B patients will be submitted to intra-aortic balloon.

\section{Method:}

All patients were evaluated thoroughly preoperative, intraoperative and postoperative, especially the duration of mechanical ventilation, use of inotropes, hospital stay and mortality.

\section{Inclusion Criteria:}

1. Patients with LVEF $\leq 35 \%$ who are undergoing first time, elective coronary artery bypass grafting with or without concomitant mitral valve intervention with the use of cardiopulmonary bypass. 
2. Pre-operative echocardiography revealed poor left ventricular function Ejection fraction less than $35 \%$.

\section{Exclusion Criteria:}

1. Severe form of COPD.

2. Renal failure or hepatic impairment.

3. Redo cases.

4. Emergency cases.

5. Extensive peripheral vascular disease.

6. Previous stroke.

7. The use of platelet alterating medications within one week of operation.

8. Post-operative myocardial infarction proved by ECG and cardiac enzymes .

All patients will subjects to the following:

\section{Preoperative evaluation:}

A. History taking: a through history will taken; as regards age, sex, and functional class according to the New York Heart association (NYHA), Data were registered in a detailed report card, including diagnosis, risk factors for coronary disease (systemic arterial hypertension, diabetes mellitus).

B. Clinical examination: a complete clinical general and local cardiological examination will performed including (Heart rate, Rhythm, Blood pressure, Chest and heart auscultation). The examination for exclusion of any comorbidity was done.

\section{Investigations:}

\section{a. Laboratory investigations:}

i. Liver function tests (total bilirubin ,liver enzymes, serum albumin, total proteins, prothrombin time and concentration) .

ii. $\mathrm{CBC}$

iii. Kidney function tests (serum urea and creatinin). iv. Fasting blood sugar ,2h post prandial blood glucose level HBA1C

\section{b) Electorcardiogram:}

12 leads ECG will be done for all patients to evaluate any previous myocardial infarctions.

c) Radiological examination:

Plain chest $\mathrm{X}$-ray postero anterior view to evaluate cardiothoracic ratio and the different cardiac chambers.

\section{d) Echocardiography:}

M mode, two dimension and Doppler echocardiography were done to each patient, the ejection fraction and valvular affection to evaluate and give comment about there is any mitral affection or not, the most important data is to asses the dimension of the heart (end diastolic and end-systolic) to know whether the heart is dilated or not, also assessment of the regional wall motion abnormality (a kinetic , dyskinetic , hypokinetic area of the heart), right ventricular function, TAPSI (tricuspid annular plane systolic excursion ).

\section{e) Viability study (dobutamin stress Echo or thallium):}

To evalaute and asses myocardial viability if there is hibernating myocardium tissues with impaired flow and function but viable and will benefit from the surgery .

\section{f) Coronary angiography :}

Coronary angiography was done to all patients. The number of diseased vessels and site of lesions were estimated .

Standard anesthetic, surgical and CPB techniques were employed.

In Group A Levosimendan was administered for approximately 24 hours as 
a continuous infusion of $0.1 \quad \mathrm{~g} / \mathrm{kg} / \mathrm{min}$ diluted in $5 \%$ glucose with a $0.25-\mathrm{mg} / \mathrm{mL}$ concentration, without boluses, through a central venous catheter. norepinephrine is almost always used to avoid severe peripheral circulatory failure.

In Group B, An IABP was inserted percutaneously, without a sheath in all patients, and removal of the device was always performed in the ICU. IABP support discontinuation progressively according to ICU protocol. Either levosemindan or an IABP was conducted immediately after induction of anesthesia before skin incision.

The CABG was performed by median sternotomy, using LITA and left pleurotomy, complemented with additional saphenous vein grafts. The anesthetic technique employed was the normal system used in the services. All patients were ventilated with current volume from 8 to $10 \mathrm{ml} / \mathrm{kg}$, PEEP of $5 \mathrm{~cm} \mathrm{H} 2 \mathrm{O}$ and $\mathrm{FiO} 2$ of $100 \%$. All patients receive intermittent antegrade blood cardioplegia, dose to every graft anastomosis.

At the end of the surgery, the patients were taken to the postoperative cardiac ICU with oro-tracheal intubation (OTI). Initially, they were ventilated with $100 \% \mathrm{FiO} 2$, with a volume of from 8 to $10 \mathrm{ml} / \mathrm{kg}$, PEEP of 5 $\mathrm{cmH} 2 \mathrm{O}$ and extubated according to the protocol of the unit.

\section{Operative parameters:}

The following data will be recorded:

1. Cross clamp time.

2. Total bypass time.

3. Number and types of grafts done.

4. Weaning of bypass was it eventless or complicated.

5. Inotropic support.

6. Mitral procedure if present.

\section{Post-operative assessment:}

The patients in two groups were reevaluated according to:

- Hemodynamics.

- Inotropic support.

- Ventilation time and time of extubation .

- Postoperative bleeding.

- Arrythmais.

- Blood products transfusion.

- Complications (Liver dysfunction, Renal impairment, Pulmonary complications, Mediastintis and rewiring and Acute limb ischemia)

- Total ICU stay.

- laboratory investigations: CBC, liver function test, kidney function test, fasting blood sugar, serum electrolytes .

- Hospital stay and Mortality.

\section{Ethical Consideration}

Written informed consents were obtained from the subjects about the nature and the aim of the study.

\section{Statistical analysis:}

Data will statistically described in terms of rang, mean, standard deviation (SD), frequencies (number of cases) and relative frequencies (percentages). The comparison between patient outcomes will be done regarding specific indicators and postoperative complications. Comparison of quantative variables between the study two groups was done using The Mann-Whitney U test, Chi square $\left(x^{2}\right)$ test was performed for qualitative variables. A probability value (P-value) less than 0.05 was considered statistically significant.

Data entry and statistical analysis will be done using statistical package for social science (SPSS). 


\section{RESULTS:}

\section{Preoperative Assessment:}

Table (1): Demographic data and clinical characteristics of the patients.

\begin{tabular}{|c|c|c|c|}
\hline Variable & Group (A) & Group (B) & p value \\
\hline no of patients & 30 & 30 & $\mathrm{~ns}$ \\
\hline $\begin{array}{c}\text { sex } \\
\text { (male/female) }\end{array}$ & $24 / 6$ & $27 / 3$ & $\mathrm{~ns}$ \\
\hline Age & $57.7 \pm 4.8$ & $58.8 \pm 4.2$ & $\mathrm{~ns}$ \\
\hline BMI & $30 \pm 3.4$ & $29 \pm 3.5$ & $\mathrm{~ns}$ \\
\hline D.M & 21 & 23 & $\mathrm{~ns}$ \\
\hline HTN & 18 & 21 & $\mathrm{~ns}$ \\
\hline EF & $4.32 \pm 2.1 \%$ & $33.1 \pm 1.7$ & $\mathrm{~ns}$ \\
\hline
\end{tabular}

Group A = Levosemindan group, Group B = IABP group, NS = Not significant

Regarding the sex, in group $A$, there was 24 males $(80 \%), 6$ females $(20 \%)$, and in group B , there was 27 males $(80 \%)$, and 3 females(10 \%), with no statistical significance between the two groups .

In group A , Age ranged from 50 to 68 years with a mean of $57.7 \pm 4.8$ years, While in group $\mathbf{B}$, age ranged from 49 to 66 years with a mean of $58.8 \pm 4.2$ years There was no statistical significance between the two groups

BODY MASS INDEX in group $A$ range from 23.3 to 36.31 with mean $30 \pm 3.4$ in group B range from 22.4 to 35.72 with mean 29. \pm 3.5 , There is no statistical significance between both groups.

Preoperative patients co-morbidities in the study were the following: In group A, 21 patients were diabetic $70 \%, 18$ patients were hypertensive $(60 \%)$. While in group B, 23 patients were diabetic $(76.6 \%), 21$ patients were hypertensive (70\%). There was no statistical significance regarding the co morbidities between the two groups.

\section{Intra-operative Evaluation:}

The total Bypass time was calculated for all patients, the mean bypass time in group A was range from 60-135 minute with mean $85.4 \pm 20.99$ minutes. In group B range from 67-133 minute with mean $90.7 \pm$ 20.4 minutes and the mean aortic crossclamp time (ACC) was 51.3 \pm 22.1 minutes among group A compared to $45 \pm 20$ minutes in group B.

Number of grafts: In our study group number of grafts in group $\mathbf{A}$ is ranging from 1 to 4 with a mean of $3.2 \pm 0.48$, While group $\mathbf{B}$ had a number of grafts ranging from 1 to 4 with a mean of $3.3 \pm 0.47$ there was no statistical significance between the two groups.

Correction of valve pathology 6 patients in group A and 4 patients in group B had mitral repair for grade III/IV mitral regurgitation using three $\mathrm{D}$ rings or valve replacemnt) There was no statistical significance between the two groups.

Perioperative and postoperative hemodynamic data. 
Table (2): Perioperative and postoperative hemodynamic data.

\begin{tabular}{|c|c|c|c|c|c|c|c|c|}
\hline & \multicolumn{2}{|l|}{ Baseline } & \multicolumn{2}{|c|}{2 hours after $\mathrm{CPB}$} & \multicolumn{2}{|c|}{6 hours after $\mathrm{CPB}$} & \multicolumn{2}{|l|}{ POD1 } \\
\hline & $\begin{array}{l}\text { Group } \\
\text { (A) }\end{array}$ & Group (B) & $\begin{array}{l}\text { Group } \\
(\mathrm{A})\end{array}$ & $\begin{array}{l}\text { Group } \\
\text { (B) }\end{array}$ & $\begin{array}{l}\text { Group } \\
\text { (A) }\end{array}$ & $\begin{array}{l}\text { Group } \\
\text { (B) }\end{array}$ & $\begin{array}{l}\text { Group } \\
\text { (A) }\end{array}$ & $\begin{array}{l}\text { Group } \\
\text { (B) }\end{array}$ \\
\hline \multirow{2}{*}{$\begin{array}{l}\text { MAP } \\
(\mathrm{mmHg})\end{array}$} & $82.8 \pm 7.8$ & $79 \pm 8.75$ & $79.8 \pm 7.9$ & $84.77 \pm 8.7$ & $78.77 \pm 7.4$ & $79.5 \pm 9.7$ & $82.6 \pm 7.5$ & $81.8 \pm 9.2$ \\
\hline & \multicolumn{2}{|c|}{$\mathrm{P}$ value $=0.081(\mathrm{NS})$} & \multicolumn{2}{|c|}{$\begin{array}{l}\mathrm{P} \text { value }=0.02 \\
\text { (significant) }\end{array}$} & \multicolumn{2}{|c|}{$\begin{array}{l}\mathrm{P} \text { value }=0.74 \\
(\mathrm{NS})\end{array}$} & \multicolumn{2}{|c|}{$\begin{array}{l}\mathrm{P} \text { value }=0.76 \\
(\mathrm{NS})\end{array}$} \\
\hline \multirow[t]{2}{*}{$\begin{array}{l}\text { CVP } \\
(\mathrm{mmH})\end{array}$} & $\begin{array}{l}10.1 \\
\pm 1.89\end{array}$ & $9.66 \pm 1.9$ & $10.4 \pm 1.9$ & $9.8 \pm 1.8$ & $9.3 \pm 1.95$ & $8.9 \pm 1.8$ & $9 \pm 0.96$ & $8.6 \pm 1.14$ \\
\hline & \multicolumn{2}{|c|}{$\begin{array}{l}\mathrm{P} \text { value }=0.33 \\
(\mathrm{NS})\end{array}$} & \multicolumn{2}{|c|}{$\mathrm{P}$ value $=0.23(\mathrm{NS})$} & \multicolumn{2}{|c|}{$\begin{array}{l}\mathrm{P} \text { value }=0.55 \\
(\mathrm{NS})\end{array}$} & \multicolumn{2}{|c|}{$\begin{array}{l}\mathrm{P} \text { value }=0.13 \\
(\mathrm{NS})\end{array}$} \\
\hline \multirow[t]{2}{*}{$\begin{array}{l}\mathrm{HR} \\
\text { (beat/ min) }\end{array}$} & $\begin{array}{l}67.5 \\
\pm 6.6\end{array}$ & $\begin{array}{l}68.4 \\
\pm 10.5\end{array}$ & $80.2 \pm 8.5$ & $82.4 \pm 10.5$ & $84.6 \pm 9.1$ & $78.3 \pm 11.5$ & $\begin{array}{l}90.6 \pm \\
9.3\end{array}$ & $\begin{array}{l}83.3 \\
\pm 6.8\end{array}$ \\
\hline & \multicolumn{2}{|c|}{$\mathrm{P}$ value $=0.67(\mathrm{NS})$} & \multicolumn{2}{|c|}{$\mathrm{P}$ value $=0.42(\mathrm{NS})$} & \multicolumn{2}{|c|}{$\mathrm{P}$ value $=0.34(\mathrm{NS})$} & \multicolumn{2}{|c|}{$\begin{array}{l}\mathrm{P} \text { value }=0.008 \\
(\text { Significant })\end{array}$} \\
\hline
\end{tabular}

Group A = Levosemindan group, Group B = IABP group

$\mathrm{CVP}=$ central venous pressure, $\mathrm{IABP}=$ intra-aortic balloon pump, Levo $=$ levosimendan, $\mathrm{MAP}=$ mean arterial pressure, $\mathrm{PAP}, \mathrm{POD}=\mathrm{POD}=$ postoperative day, $\mathrm{HR}=$ heart rate

The most important finding after analyzing the hemodynamic parameter of the patients in the two groups was the significant difference in the mean arterial pressure. Also at 2 hours after CPB mean arterial pressure decreased significantly in the levosimendan group. As shown in table (2).

Table (3): Post-operative data in the study groups:

\begin{tabular}{|c|c|c|c|}
\hline Variable & Group (A) & Group (B) & P Value \\
\hline ICU stay & $4.4 \pm 0.77$ & $5.2 \pm 0.85$ & S \\
\hline MV time(hours) & $11.1 \pm 2.4$ & $11.9 \pm 3.3$ & NS \\
\hline Arrhythmia & 6 & 4 & NS \\
\hline Dialysis & Zero & 1 & NS \\
\hline Reopening & 1 & 2 & NS \\
\hline Mediastintis & 1 & 1 & NS \\
\hline Death & 2 & 3 & NS \\
\hline HOSPITAL stay & $10.6 \pm 1.15$ & $11 \pm 1.08$ & NS \\
\hline
\end{tabular}

\section{The need for inotropes:}

All patients in our study were on inotropic support, there was NO statistical significance between the two groups in dose of inotropic support or time of weaning from inotropes.

\section{III - Post -operative Evaluation:}

All patients were admitted to cardiothoracic ICU postoperatively were on mechanical ventilation. The post-operative mechanical ventilation time ranged from 9 to 18 hours with a mean of $11.1 \pm 2.4$ hours in group A, while in group B time ranged from 8 to 21 hours with a mean of $11.9 \pm 3.3$ hours. There was no statistical significance between the two groups ( $\mathrm{p}$ value >0.05).

( Tarate 
$30-49 \%$ with the mean of $32.2 \pm 2.1$, While in group $\mathbf{B}$, all the patients have ejection fraction ranged from $31-50 \%$ with the mean of $38.7 \pm 4.6 \%$, There was NO statistical significance between the two groups.

\section{Intensive Care Unit stay:}

In our study group A ICU stay is ranging from 3 to 6 days with a mean of 4.4 \pm 0.77 day, while group $B$ had ICU stay ranging from 4 to 7 days with a mean of 5.2 \pm 0.85 day, there was statistical significance between the two groups.

\section{Postoperative arrhythmia:}

In our study group A, six (6) patients had postoperative arrhythmia in the form of rapid AF amiodarone infusion was added, while in group B four (4) patients had postoperative arrhythmia in the form of rapid AF, Premature ventricular contractions, there was No statistical significance between the two groups.

\section{Postoperative dialysis:}

In our study group $\mathbf{A}$, NO patient had postoperative dialysis, while in group $\mathbf{B}$ one patient had postoperative dialysis three time in cardio-thoracic ICU then patient died, there was No statistical significance between the two groups.

\section{Bleeding:}

The difference between the mean postoperative bleeding in both groups was statistically significant, as the mean blood loss volume was $395.00 \pm 220.55 \mathrm{ml}$ in group A compared to $645.45 \pm 261.36 \mathrm{ml}$ in group B $(39 \%$ reduction in blood loss in group A). But only one patients in group A and two patients in group B were reexplored for bleeding, the difference regarding re-opening in both groups was not statistically significant. When comparing the total transfusion requirements in each group during the whole post-operative period, there was a highly significant statistical difference between both groups as regards the number of patients needed transfusion and number units of all blood constituents transfused especially platelet transfusion.

One patient in the Levosmindan group and 1 in the IABP grou developed mediastinitis postoperatively.

\section{Failure of primary method of intervention:}

In our study, 3 patients in group A needed an IABP due to difficult weaning from $\mathrm{CPB}$ versus 2 patients in group $\mathrm{B}$, levosemindan infusion was started due to difficult extubation. there was No statistical significance between the two groups.

\section{Death:}

In our study group $\mathbf{A}$, two patients died from multi-organ failure due to low cardiac output syndrome, one patient died at postoperative day 4 and the other at postoperative day 6, While in group $\mathbf{B}$ three patients died, one patient developed acute renal failure and died at post-operative day 5 , the other two patients died from multiorgan failure due to low cardiac output syndrome, one patient died at post-operative day 5 and the other at post-operative day 6, there was No statistical significance between the two groups.

\section{Hospital stay:}

In our study group A HOSPITAL STAY is ranging from 9 to 13 days with a mean of $10.66 \pm 1.15$ day, while group $\mathbf{B}$ HOSPITAL STAY had ranging from 10 to 14 days with a mean of $11 \pm 1.08$ day, there was NO statistical significance between the two groups.

\section{DISCUSSION:}

Patients with cardiovascular and systemic condions (ischemic heart disease, particularly whose an ejection fraction of less than $35 \%$ ( LV dysfunction), form a major challenge for anesthesiologists and cardiothoracic surgeons, emphasizing the need for risk stratification and prophylactic 


\section{Shereif Elsayed Soliman Azzab, et al.,}

measures to decrease postoperative morbidity and mortality.

At present, intra-aortic balloon pump (IABP) is the most commonly used device for circulatory assistance in cardiac surgery and preoperative prophylactic IABP use has been shown to improve outcomes in highrisk patients and is supported by a large amount of data ${ }^{(9)}$.

The intra-aortic balloon pump works by increasing diastolic blood pressure, directly improving diastolic coronary perfusion and increasing cardiac output and stroke volume by reducing afterload. The ability to work on diastolic pressure has a great importance in clinical practice because of the augmented diastolic pressure results in a redistribution of coronary blood flow direcional to ischemic areas of the cardiac myocardium $^{(10)}$.

Many studies reported the advantage of prophylactic IABP insertion in high-risk patients undergoing open heart surgery. It has been shown to decrease postoperative mortality. Dyub et al. reported that patients who received prophylactic IABP preoperatively had a mortality benefit with an odds ratio (OR) of 0.41 (95\% CI $0.21-0.82$; $\mathrm{p}=0.01$ ), but it had not been established as the gold standard for high-risk CABG. One of the reasons was complications ${ }^{(11)}$.

Patients undergoing IABP insertion, however, have been classified at higher risk for rebleeding, and prolonged ventilation, as well as at increased risk of reintubation, tracheostomy, dialysis, prolonged ICU stay and thromboembolic complications ${ }^{(12)}$.

Levosimendan has a pharmacodynamic profile combining inotropic and vasodilating effects (inodilator), and a nearly unique (among inotropes) myocardial protective effect. The inotropic effect results, in part, from an increased affinity of troponin $\mathrm{C}$ for calcium when the drug is present, which in turn prolongs the duration of actin/ myosin cross-bridges. This explains an increased contractility which is not associated with a raise in intracytoplasmic calcium concentration. Therefore, this inotropic effect does not generate a direct significant increase in myocardial oxygen consumption, since most of the myocardial energy expenditure is related to the diastolic uptake of calcium in the sarcoplasmic reticulum. However, levosimendan and its metabolite have also been shown to inhibit phosphordiesterase III, an action that may participate to the positive inotropic effect via the cAMP pathway, but that might, in turn, increase myocardial oxygen consumption. Levosimendan is a potent vasodilator through the opening of ATP dependent potassium channels in vascular smooth muscles. It has been associated with a variety of myocardial protective effects against ischemia (pre-conditioning, postconditioning, anti-stunning, and antiapoptotic effects) that are related to the opening of the same channels within the mitochondria of cardiac myocytes ${ }^{(13)}$.

From the pharmacokinetic point of view, levosimendan has a fast onset of action and a half-life of $1 \mathrm{~h}$. The drug undergoes hepatic metabolism (acetylation) followed by renal excretion. Quite uniquely, it has an active metabolite with a very long half-life $(70-80 \quad h)$ responsible for a prolonged effect. All these characteristics offer opportunities to provide an ideal therapeutic response to specific situations. Nevertheless, the longer half-life, as compared to catecholamines, may change the way clinicians manage side effects (e.g., arterial hypotension) and may sometimes prove inconvenient when quick reversibility is desirable. The most frequent adverse event associated with levosimendan administration is hypotension requiring norepinephrine infusion, although its prevalence was not significantly greater with respect to dobutamine in the largest randomized controlled trials published ${ }^{(14)}$. 
Due to a very interesting pharmacological profile, levosimendan has raised a lot of interest in the field of heart failure management. a recent meta-analysis suggested that there could be a greater benefit in the preoperative infusion of levosimendan prior to CABG surgery in patients with poor $\mathrm{LVEF}^{(15)}$.

Our study included 60 patients with impaired LV function needing CABG surgery with or without concomitant ischemic mitral repair and receiving either i)-preoperative Levosimendan as a continuous infusion at a rate of $0.1 \mu \mathrm{g} /$ $\mathrm{kg} / \mathrm{min}$ without loading, or ii)-an IABP just after induction of anesthesia.

At that infusion rate the levosemindan itself reaches a linear concentration in blood after 4 hours while its active metabolite, OR1896 , continues in blood to a peak level about 48 hours and achieves a half-life of about 80 hours after the end of the infusion, covering the most critical postoperative period after CABG surgery until complete recovery of the ischemic myocardium. This strategy appears successful in avoiding the adverse effects of the drug.

Although the use of IABP prior to CABG surgery in high risk patients especially those with low LVEF has been shown in many studies to improve surgical outcomes in terms of in-hospital mortality, postoperative hemodynamic parameters and ICU stay. Yet IABP application is in general an invasive procedure that might be associated with some adverse effects like limb ischemia and bleeding ${ }^{(16)}$.

In our study, there was a significant increase in transfusion requirements in group B. Because of heparin infusion and the destructive effect of the IABP, a significant increase of daily drainage amount, decrease of hemoglobin level and platelet count were statistically different in group B with no difference between the 2 groups according to re-exploration.
Vladimir V Lomivorotov and collagues reported that no statistical significance according to blood loss or re-exploration but they did not report transfusion requirements in their study ${ }^{(17)}$.

Landoni and colleagues showed in a recent meta-analysis that the use of levosimendan contributes to a significant reduction of mortality in cardiac patients. The results of our study demonstrate that starting levosimendan infusion after induction of anesthesia is a good alternative to IABP in high-risk cardiac patients. However, mortality and the frequency of other major complications as renal failure were not different between our 2 groups. Luca Severi and collagues reported that no statistical significance of the need for dialysis $^{(18)}$.

In our study group A mean ICU stay was $4.4 \pm 0.77$ hour, while in group $\mathrm{B}$ was $5.2 \pm 0.85$ hour, there was statistical significance between the two groups. Vladimir V Lomivorotov and collagues and Luca Severi and collagues also reported statistical significance ${ }^{(17,18)}$.

Rajek and colleagues were the first to report the use of levosimendan in patients with congestive heart failure and a preoperative left ventricular ejection fraction of $19 \pm 5 \%$ undergoing elective cardiac surgery. There was a dramatic increase in $\mathrm{CO}$ after 60 minutes of levosimendan infusion and it stayed higher than $5 \mathrm{~L} / \mathrm{min}$ during the first postoperative day, while pulmonary capillary wedge pressure (PCWP) decreased. Heart rate, mean arterial pressure (MAP), and pulmonary arterial pressure did not change during levosimendan infusion.

Several studies have suggested that levosimendan could be helpful to prevent LCOS and reduce morbidity and mortality after cardiac surgery. A recent meta-analysis of perioperative use of levosimendan confirmed that the efficacy of levosimendan 
seems to be more pronounced in patients with preoperative left ventricular dysfunction ${ }^{(19)}$.

Tasouli et al, have presented a study where 45 patients with LOS were randomized to receive levosimendan either in the operating $\operatorname{room}(\mathrm{OR})$ or in the ICU. Hemodynamic responses were similar in the two groups, but the OR group had significantly shorter ICU and hospital stay $^{(18)}$.

In our study, significantly higher heart rate at postoperative day one after $\mathrm{CPB}$, this comes in favor with the previous studies concluding the potent inotropic and vasodilatory effect of Levosimendan. Mean arterial pressure decreased significantly in the levosimendan group compared to the IABP group at 2 hours after CPB.

Post-operative arrhythmia no statistical significance between both groups. Vladimir V Lomivorotov and collagues, Luca Severi and collagues also reported NO statistical significance.

Three patients in levosemindan group had unstable hemodynamics after coming off-bypass and IABP was inserted in the 2 patients. However, 2 patients in IABP group had difficult intubation and levosemindan infusion was started. As respiratory muscle troponin resembles cardiac troponin, it is plausible that levosimendan may enhance contractility in the same way it enhances cardiac contractility. This supposition has support from in vitro data, experimental observations, and a healthy volunteer study. Positive effects were seen both in slow and rapid diaphragm muscle fibers.

Van Hees and collegues, in a prospective observational study in ventilator-dependent difficult-to-wean ICUpatients with diminished left ventricular function (LVEF <40\%), levosimendan improved cardiac contractility and oxygenation variables and increased the likelihood of separation from mechanical ventilation $^{(20)}$.

\section{Conclusion:}

With taking all the available data into consideration we found levosimendan infusion after induction of anesthesia is a good choice with an acceptable option in comparison to IABP. The use of levosimendan in high-risk cardiac patients is comparable to IABP in improving hemodynamics during and after conventional onpump CABG and results in a shorter ICU stay.

\section{REFERENCES:}

1. Adams Jr KF, Fonarow GC, Emerman CL, LeJemtel TH, Costanzo MR, Abraham WT, et al 2005. Characteristics and outcomes of patients hospitalized for heart failure in the United States: rationale, design, and preliminary observations from the first 100000 cases in the Acute Decompensated Heart Failure National Registry (ADHERE). Am Heart J; 149: 209-216.

2. O'Connor CM, Velazquez EJ, Gardner LH, Smith PK, Newman MF, Landolfo KP, et al 2002. Comparison of coronary artery bypass grafting versus medical therapy on long-term outcome in patients with ischemic cardiomyopathy (a 25-year experience from the Duke Cardiovascular Disease Databank). Am J Cardiol; 90: 101107.

3. Antonio Miceli, Brenno Fiorani, Tommaso Hinna Danesi 2009; prophylactic intraaortic ballon pump in high risk patients under gioning coronary artery bypass grafting: a propensity score analysis, Oxford Journals Medicine \&Health Interactive CardiovascThoracic surgery volume 9, issue2 ,Pp.291-294..

4. Raja SG, Rayen BS 2006. Levosimendan in cardiac surgery: current best available evidence. Ann Thorac Surg;81(4):1536-46.

5. Lazar, H.L., Yang, X.M., Rivers, S., Treanor, P., Bernard, S. and Shemin, R.J. (1992) Retroperfusion and Balloon Support to Improve Coronary Revascularization. 
The Journal of Cardiovascular Surgery , 23, 538-544.

6. Rogers, W.J., Coggin, C.J. and Gersh, B.J. (1990) Ten Year Follow-Up of Quality of Life in Patients Randomized to Receive Medical Therapy or Coronary Artery Bypass Graft Surgery: The Coronary Artery Surgical Study (CASS). Circulation, 82, 1647-1660

7. Marco Ranucci, S.Donato 2012; Perioperative Intra Aortic Balloon Pump (IABP) in Coronary Artery Bypass Grafting (CABG) operations in patients with severe depressed left ventricular function, clinical trials .gov,.

8. Ozgur Erosy ,MD, Emre Boysan, MD, Keremyay, MD et al 2013; effectiveness of prophylactic Levosimendan in high risk valve surgery patients, Cardiovasc J AFR.Oct;24(7):260-264,.

9. Dyub AM, Whitlock RP, Abouzahr LL and Cina CS. 2019 Preoperative intra-aortic balloon pump in patients undergoing coronary bypasss surgery: A systematic review and meta-analysis. J Card Surg; 23:79-86.

10. Parissis H, Leothinidis M, Akbar MT, Apostolakis E and Dougenis D 2010. The need for intra-aortic balloon pump support following open heart surgery: Risk analysis and outcome. J Cardiothorac Surg.; 5:20-28.

11. Harrison RW, Hasselblad V, Mehta RH, Levin R, Harrington RA and Alexander JH 2013. Effect of levosimendan on survival and adverse events after cardiac surgery: a meta-analysis. J Cardiothorac Vasc Anesth; 27:1224-32.

12. Lim JY, Deo SV, Rababa'h A, Altarabsheh SE, Cho YH, Hang D, et al 2015. Levosimendan reduces mortality in adults with left ventricular dysfunction undergoing cardiac surgery: a systematic review and meta-analysis. J Card Surg;30:547-554.

13. Mehta RH, Leimberger JD, van Diepen S, Meza J, Wang A, Jankowich R, Harrison RW, Hay D, Fremes S, Duncan A, et al 2017. Levosimendan in patients with left ventricular dysfunction undergoing cardiac surgery. New Engl J Med; 376:2032-42.
14. Rampersad PP, Udell JA, Zawi R, Ouzounian M, Overgaard CB, Sharma V, et al 2018. Preoperative Intraaortic Balloon Pump Improves Early Outcomes Following High-Risk Coronary Artery Bypass Graft Surgery: A Meta-Analysis of Randomized Trials and Prospective Study Design. J Invasive Cardiol.; 30:2-9.

15. Vladimir V Lomivorotov, Alexander $\mathrm{M}$ Cherniavskiy, et al 2011. Levosimendan vs. intra-aortic balloon pump in high-risk cardiac surgery. Asian Cardiovascular \& Thoracic.; 19(2) 154-159.

16. Luca Severi, Angela Lappa, Giovanni Landoni, Lucio Di Pirro, et al 2011. Levosimendan Versus Intra-aortic Balloon Pump in High-Risk Cardiac Surgery Patients. Journal of Cardiothoracic and Vascular Anesthesia;:25: pp 632-636.

17. Rajek AM, Koinig H, Jelen M, Schiferer and Hutschala D 2003. Levosimendan, a new Ca-sensitizer, in patients with poor left ventricular function undergoing cardiac surgery Anesthesiology;99: A133abstract.

18. Tasouli A, Papadopoulos K, Antoniou T, Kriaras I, Stavridis G, et al 2007. Efficacy and safety of perioperative infusion of levosimendan in patients with compromised cardiac function undergoing open-heart surgery: importance of early use. Eur $\mathbf{J}$ Cardiothorac Surg.;32: 629-633.

19. Cholley B, Caruba T, Grosjean S, Amour J, Ouattara A, Villacorta J, Miguet B, Guinet P, Levy F, Squara P, et al 2017. Effect of levosimendan on low cardiac output syndrome in patients with low ejection fraction undergoing coronary artery bypass grafting with cardiopulmonary bypass: the LICORNrandomized clinical trial. JAMA.;318:548-56.

20. Russ MA, Prondzinsky R, Carter JM, Schlitt A, Ebelt H, Schmidt H, Lemm H. et al 2009. Right ventricular function in myocardial infarction complicated by cardiogenic shock: Improvement with levosimendan. Crit Care Med.;37(12): 3017-3023. 
مقارنة في استخذام عقار الليفوسميندان ومضخة الشريان الأورطي في عمليات زراعة الشرايين في

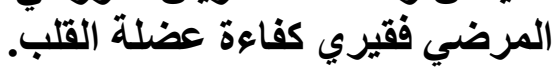

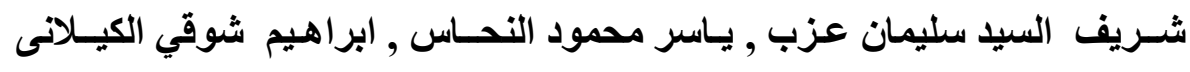

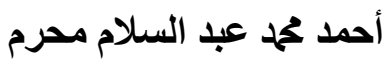

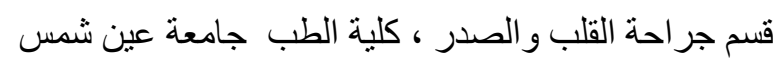

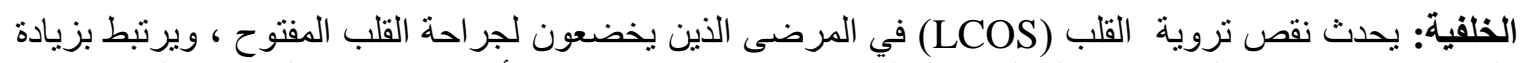

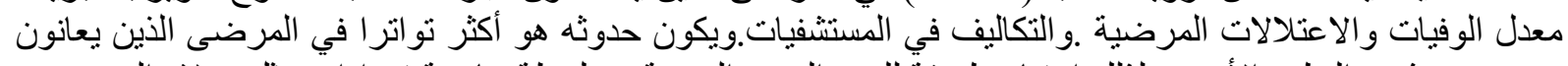

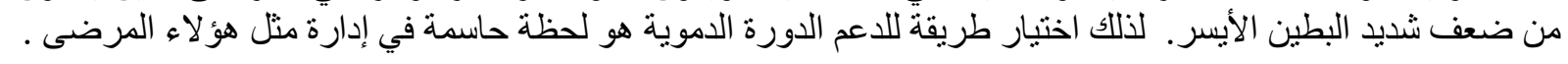

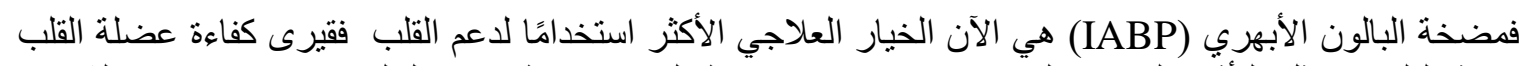

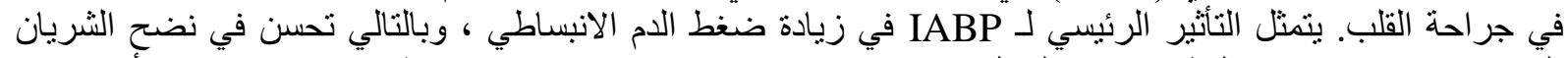

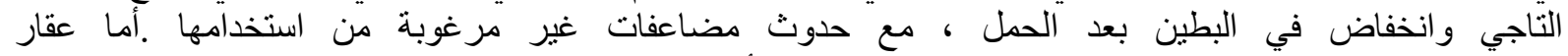
ال Levosimendan الكستخدم حديثا حيث يلقي رواجا لما له تأثير إيجابي على كفاءة القلب دون الاحتياج لاستهلاك مزيد الكاري

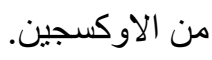

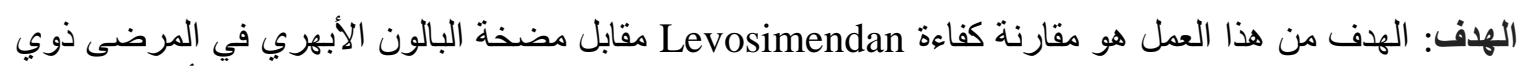

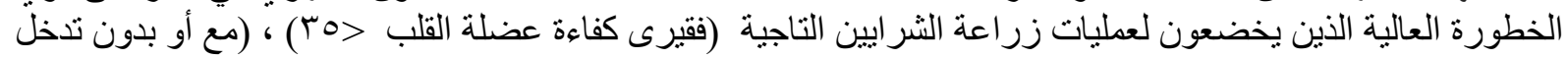

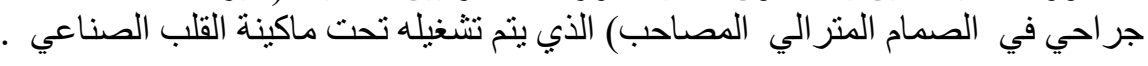

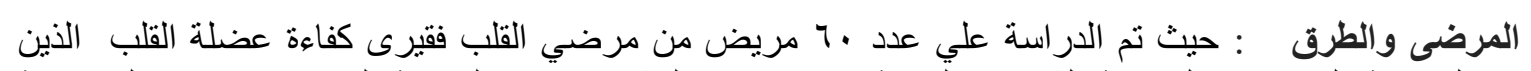

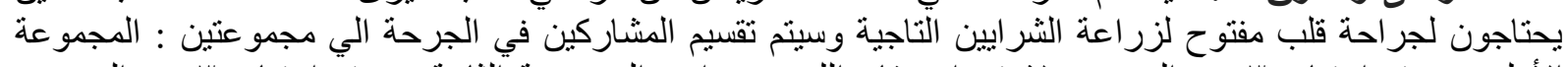

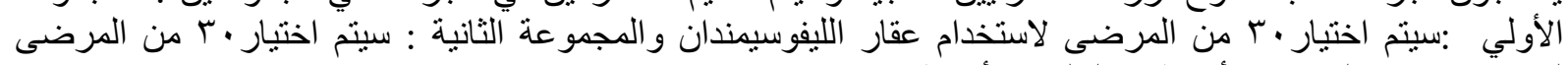

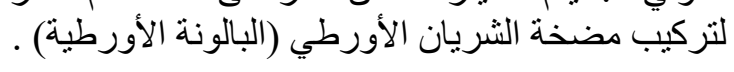

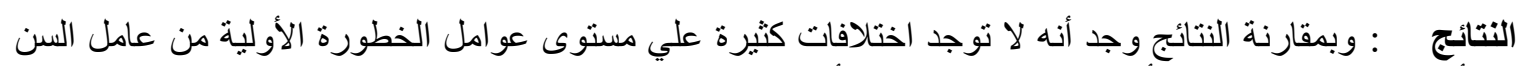

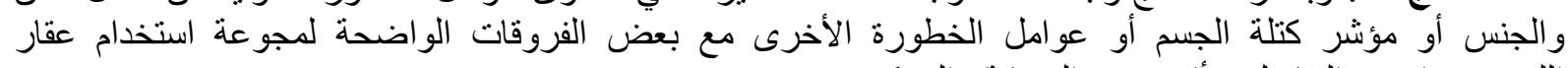

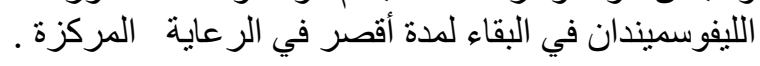

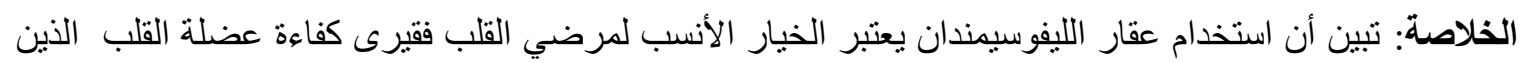

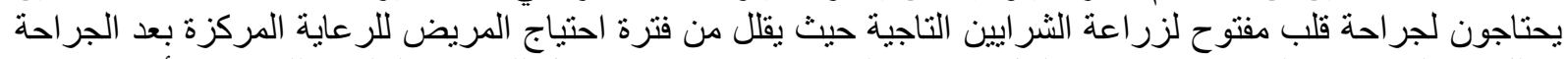

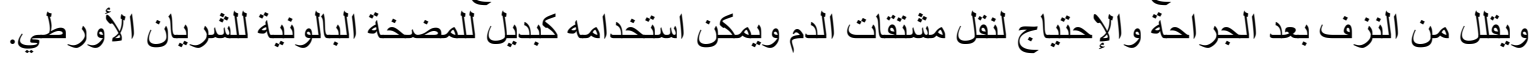

